\title{
Response to "Income, sustainability and the 'microfoundations' of the GPI"
}

\author{
Philip Lawn \\ Faculty of Social Sciences \\ Flinders University \\ GPO Box 2100, Adelaide, SA, 5001, Australia \\ Fax: +61 882012644 \\ E-mail: phil.lawn@flinders.edu.au
}

\begin{abstract}
The Genuine Progress Indicator (GPI) is an experiential welfare indicator based on an extended version of Fisher's distinction between income and capital. The primary aim of the GPI is to measure the difference between the net psychic income generated by economic activity (uncancelled benefit) and the natural capital services lost as a consequence of fuelling the economic process (uncancelled cost). Provided this is achieved with some degree of accuracy, the GPI is able to: (a) represent the value added to nature by the economic process; (b) determine whether growth of the economy, if it is presently occurring, is 'economic' or 'uneconomic'; and (c) signal when an economy has exceeded its optimal macroeconomic scale. Nevertheless, there is little doubt that the GPI fails to strictly satisfy the central criterion embodied in the Hicksian concept of income. As such, the GPI is incapable of signalling when an economy has surpassed its maximum sustainable scale. But neither can so-called measures of Hicksian income (e.g., Net National Product (NNP)) since they, too, violate Hicks' central criterion. For this reason, indicators of sustainability are best left to measures of wealth/capital or, better still, comparisons between a nation's ecological footprint and biocapacity.
\end{abstract}

Keywords: Genuine Progress Indicator; Fisherian income; Hicksian income; central criterion; sustainability.

Reference to this paper should be made as follows: Lawn, P. (2008) 'Response to "Income, sustainability and the "microfoundations' of the GPI", Int. J. Environment, Workplace and Employment, Vol. 4, No. 1, pp.59-81.

Biographical note: Philip Lawn is a lecturer in environmental and ecological economics at Flinders University. Over the past nine years Philip has published a number of papers on ecological economics issues as well as a book entitled Toward Sustainable Development (2000) and another edited volume entitled Sustainable Development Indicators in Ecological Economics (2006). Philip is currently working on environmental macroeconomic models and a comprehensive set of sustainable development indicators to assess Australia's sustainable development performance. Some of this latest work appears in a recently published book entitled Frontier Issues in Ecological Economics (2007). 


\section{Introduction}

The Genuine Progress Indicator (GPI) is a composite indicator which has been developed to overcome the inability of conventional macroeconomic indicators - such as Gross Domestic Product (GDP) — to reflect the economic welfare generated by national economies. Appearing in a recent special issue of this journal (Volume 3, Number 2) was an insightful paper by Harris (2008) criticising the microfoundations of the GPI and questioning whether the GPI provides the information claimed by its advocates.

Harris's paper serves as an important critique of the GPI for three reasons. Firstly, my recent attempt to provide theoretical support for the GPI was motivated by a sense that the GPI appeared to have great merit but was devoid of a theoretical foundation (Lawn, 2003). Harris's paper is a sobering reminder of how easily one can overlook some of the basic theoretical principles surrounding the income concepts used to establish such a foundation. Secondly, Harris's paper poses the greatest credible challenge yet to the GPI. If nothing else, it compels GPI advocates to reassess the validity of the GPI and to reconcile the difference between what the GPI aims to measure and what it actually measures. Having said this, I still believe the GPI remains a very useful indicator since it overcomes what I consider to be some deficiencies of Hicksian measures of national income. Thirdly, criticism of the kind made by Harris can, if properly heeded, lead to a clearer understanding of the GPI - in particular, a more robust theoretical foundation to support it — and a better GPI to potentially assist policy makers.

In order to respond to Harris's criticisms, this paper is structured as follows. For the uninitiated, I will begin by saying something about Hicksian income, Fisherian income, and the GPI. I will then summarise what I believe to be Harris's central criticism of the GPI and respond directly to it. This will be followed by responses to a number of specific points raised by Harris. Finally, I will make some general comments to clarify what information the GPI can and ought to convey, what purpose it can fulfil, and what supplementary indicators are required to better assess a nation's current economic performance and possible future direction.

\section{Hicksian income, Fisherian income, and the GPI}

Hicksian income refers to a concept of income first outlined by John Hicks (1946) namely, that the purpose of income calculations is to indicate what people can consume without impoverishing themselves. From this concept, Hicks defined income as the maximum amount that a person can consume in a week and still be as well off at the end of a week as at the beginning (Hicks, 1946, p.172). This definition of income has two distinct components: (a) "what we can consume now", and (b) "what we must do to ensure we can consume at least the same in the future". Referred to by Hicks as the 'central criterion', the second aspect is a critical feature of Hicksian income for two reasons. Firstly, satisfying the central criterion greatly restricts what can be consumed in the present. Secondly, it ensures a 'sustainability' condition is automatically embodied within the income concept itself. After all, if the present level of consumption exceeds what can be enjoyed in the future (i.e., if the central criterion is not satisfied), current consumption is effectively unsustainable. 
Following Hicks' insights, questions arose amongst economists as to whether GDP equated to Hicksian national income. Close examination revealed that GDP overstated Hicksian national income because the maintenance of a nation's productive capacity which is necessary to sustain a particular consumption level - requires a portion of a nation's annual product to be set aside to replace worn out human-made capital. That is, it was not possible for a nation to consume its entire GDP and be in a position to consume at least as much annual product in the following year. In response, some basic adjustments were made to GDP to take account of both the depreciation of human-made capital and the depletion of natural capital. This resulted in measures more commonly referred to as Net National Product (NNP), where:

$$
\mathrm{NNP}=C+\Delta K
$$

and where:

- $C=$ current consumption

- $\Delta K=$ net investment (gross investment less capital depreciation/depletion).

Despite the apparent logic behind NNP, it wasn't until Weitzman (1976) that NNP was shown to equate to Hicksian income, albeit under specific conditions. In a groundbreaking paper, Weitzman demonstrated that NNP is the stationary equivalent of future consumption. In other words, while the actual NNP of a nation will differ depending on how much of the annual product is devoted to present consumption as opposed to capital accumulation, the present value welfare of all possible $C+\Delta K$ combinations in a competitive economy is the same. In this sense, the value of NNP corresponds to the maximum welfare that could be enjoyed if capital was merely kept intact and the remaining annual product was devoted entirely to current consumption (i.e., if $\mathrm{NNP}=C$ with $\Delta K=0){ }^{1}$

Well before Hicks' inquiry into income, Fisher (1906) proposed a different view of income by arguing that 'psychic income', not consumption per se, constitutes the true purpose of economic activity. Fisher therefore believed that the national dividend should not consist of the quantity of goods consumed in any given year, but of the final subjective services that emerge in the stream of human consciousness as a consequence of consumption, or indeed any other aspect of economic life. Given the broad means by which the economic process can impact on one's stream of consciousness, Fisher believed that additional psychic income and psychic outgo elements should be included in a measure of income (e.g., the cost of labour sacrifice). By subtracting the psychic outgo from the psychic income elements, Fisher arrived at what might best be described as the net psychic income generated by economic activity.

In view of Fisher's emphasis on psychic services, Fisherian income diverges quite markedly from Hicksian income insofar as Fisherian income is purely experiential. ${ }^{2}$ That is, Fisherian income is confined to what is currently being experienced whereas, if net investment is positive (i.e., if $\Delta K>0$ ), Hicksian income also includes future consumption. This consequently leads to another important disparity between Fisherian and Hicksian income. In terms of measuring Fisherian income, any durable producer or consumer good manufactured during the current year is not counted as part of this year's income. It is only considered a balance sheet addition to the stock of human-made capital (broadly defined). Conversely, included in a measure of current income are the services rendered in the current year by existing durable producer and consumer goods. 
I mentioned in the introduction that I recently wrote a paper to theoretically support the GPI (Lawn, 2003). I did this because of the lack of such support in the GPI literature. ${ }^{3}$ In my efforts to support the GPI, I opted for the Fisherian income concept. I made this choice largely because the GPI was not consistent with the Hicksian income concept and because I believe there is considerable merit in measuring experiential welfare. Of course, employing the Fisherian income concept simply because it is better suited to the GPI does not automatically validate the theoretical foundation I expounded. This depends largely on how valid the Fisherian income concept is itself. I will take up this discussion shortly. For now, I would like to explain in what way Fisher's original income concept was extended to provide the theoretical foundation for the GPI.

A specific feature of Fisher's original concept of income is its confinement to what Daly (1979) referred to as the uncancelled benefit of economic activity - namely, the uncancelled benefit (net psychic income) that remains after all intermediate transactions involved in generating service-yielding goods have cancelled out. Daly believed it was also necessary to supplement Fisher's vision with the visions of Boulding (1966) and Georgescu-Roegen (1971) concerning the maintenance cost of human-made capital. As previously mentioned, the stock of human-made capital wears out through use and must be replaced. Whilst Fisher traced the chain of economic activity to the net psychic income it generates, he failed to trace the chain back to the uncancelled cost associated with capital maintenance. The uncancelled cost exists as the unpaid contribution of nature - that is, the natural capital services sacrificed whilst making available the throughput of matter-energy needed to keep the stock of human-made capital intact. ${ }^{4}$

Combining the theses of Fisher and Daly presents us with the following: (a) Fisher's notion of the net psychic income (economic welfare) generated by economic activity; and (b) Daly's notion of the natural capital services (economic welfare) lost in the process of fuelling economic activity. Since human beings engage in economic activity to generate a level of net psychic income greater than what nature can freely provide, the difference between net psychic income (uncancelled benefit) and lost natural capital services (uncancelled cost) effectively constitutes the value added to low entropy matter-energy by the economic process. It is this additional value which, in my view, the GPI measures (Lawn, 2000). ${ }^{5}$ In all, the GPI can be represented by the following: ${ }^{6}$

$$
\mathrm{GPI}=C+S C D-E C D+P Y-P O-L N C S
$$

where:

- $C=$ current consumption

- $S C D=$ psychic services generated by the exiting stock of consumer durables

- $E C D=$ current expenditure on consumer durables

- $\quad P Y=$ sum of additional psychic income items

- $P O=$ sum of psychic outgo items

- $L N C S=$ cost of lost natural capital services. 


\section{Harris's central criticism of the GPI}

Although Harris is critical of a number of aspects related to the GPI, his central criticism concerns the supposed failure of the GPI to say anything about the sustainability of a nation's economy. To aid his critique, Harris (pp.9 and 10) asks the reader to imagine the hypothetical mechanical devices needed to measure Hicksian national income (NNP) and Fisherian national income (GPI). In the case of the GPI, Harris suggests that psychic flows would simply be recorded as they flew by (i.e., as they were currently being experienced) and quantified in terms of some metric, such as utility. As such, the hypothetical device would be no more sophisticated than a meter which measures and nets out the flows of psychic outgo from the flows of psychic income to arrive at a measure of net psychic income.

On the other hand, Harris argues that the device designed to measure Hicksian income would be far more complex since it would measure current consumption as well as make adjustments to incorporate the impact of current consumption on future consumption possibilities. Thus, while the device used to measure the GPI would ignore the impact of current activities on service-generating capital, an appropriate recalibration function would be a central feature of the Hicksian device. As a consequence, Harris (p.10) contends that the GPI "says nothing about what might happen to consumption in the future."

What Harris is effectively saying is that the GPI fails to satisfy Hicks' central criterion. Since it is broadly accepted that appropriate national income calculations should indicate how much a nation can currently consume or experience without impoverishing itself, Harris's assertion suggests that the GPI is an inadequate income candidate or, at the very best, is an inferior measure of income to NNP.

\section{Response to Harris's central criticism}

Before I say something about whether the GPI contains sustainability information, may I begin by saying that the GPI was never intended to be a sustainability indicator. This is despite the emphasis placed by GPI advocates on 'thresholds' and the implication that the GPI contains sustainability information within it because it has evolved from the previously named Index of Sustainable Economic Welfare (ISEW). ${ }^{7}$ I'll have more to say on this soon.

We have already seen that the calculation of the GPI includes a deduction for the uncancelled cost of economic activity which, as Equation (2) indicated, was equivalent to the cost of lost natural capital services. Apart from accounting purposes, deducting the uncancelled cost of economic activity is important for another reason. Ecological economists believe that natural capital and human-made capital are complements, not substitutes (Daly, 1996; Lawn, 1999 and 2004). Moreover, while natural capital is required in order for human-made capital to exist, the opposite doesn't hold true (i.e., iron ore is required to manufacture producer goods constructed from steel, but timber mills are not required for forests to exist). Ecological economists therefore believe that natural capital, along with human-made capital, must be kept intact to sustain the net psychic income generated by the economic process. Since the cost of lost natural capital services is effectively equal to the cost of natural capital depletion, subtracting the former when calculating the GPI means at least some of the impact of present activities on future well-being is being accounted for. Whether the GPI accounts for the full impact is 
another matter, and this will be investigated later in the paper. However, it is incorrect to say that the GPI, as an extension of Fisher's concept of income, "says nothing" about what might happen to future welfare possibilities.

Given the doubts surrounding the GPI, it is worth investigating how well NNP satisfies Hicks' central criterion. As it turns out, NNP fares quite poorly. There are various reasons for this. Firstly, NNP conflates human-made capital and natural capital. As just mentioned, the two forms of capital are inadequately substitutable and this applies even if we confine the analysis to production possibilities and ignore altogether the critical waste assimilative and life-support services provided by natural capital. Thus, keeping the combined stock of capital intact (i.e., ensuring $\Delta K=0$ ) does not guarantee a sustainable consumption flow. The following is a good demonstration of this. Imagine a nation which kept a combined stock of capital intact over a series of accounting periods. Every element of the stock remained unchanged except for fish stocks, which steadily declined; and the number of fishing boats, which steadily increased (the latter offsetting the former). Imagine, also, that the nation's consumption of fish constituted a non-trivial share of its total consumption and its total consumption had remained unchanged but only because: (a) the increased number of fishing boats (increased effort) had overcome the increased difficulty in catching fish (fewer fish caught per unit of effort); and (b) the fish population had not yet collapsed but was on the verge of doing so. This nation's NNP would remain unchanged over the period despite the impending fall in consumption. Hicks' central criterion has clearly been violated but would appear to have been satisfied according to the nation's NNP.

Secondly, the complementarity between human-made capital and natural capital exposes the myth that human-made capital is directly convertible into consumption goods. Apart from the fact that natural capital is required for human-made capital to exist, additional low entropy matter-energy, which can only be sourced from natural capital, is required to generate the consumption goods of the future. Hence, the statement by Weitzman (1976, p.156) that "investment must be treated as an intermediate good in a multiperiod system whose final products are the various consumptions of different years" only holds true if sufficient quantities of complementary forms of natural capital remain available (e.g., fish stocks to support fishing boats). That Weitzman and others (e.g., Hartwick, 1977 and 1994; Solow, 1986; Hamilton, 1994) have concluded that NNP approximates Hicksian national income is due principally to the use of Cobb-Douglas production functions in many of the analytical models which falsely assumes an elasticity of substitution of one between low entropy resources (natural capital) and human-made capital. ${ }^{8}$ Manipulation of a production function obeying the first and second laws of thermodynamics reveals that the elasticity of substitution between these two forms of capital is always less than one (Lawn, 2004).

Finally, even if an expanding stock of human-made capital could for some time offset the impact of declining natural capital, Asheim (1994) has shown that an equilibrium competitive trajectory that distributes utility in favour of generations in the near future perversely increases the relative price of human-made capital. This results in a higher valuation of investment in human-made capital relative to the depletion of natural capital. As a consequence, measured NNP exceeds the maximum sustainable flow of utility. I would add that the lack of understanding in relation to the minimal substitutability of human-made capital for natural capital probably further distorts the relative prices of the two forms of capital, particularly in futures markets, and only accentuates the disparity between the maximum sustainable flow of utility and measured NNP. 
To some extent, the GPI overcomes the problems associated with conflating humanmade capital and natural capital by ignoring the greater part or the entire change in the stock of human-made capital. ${ }^{9}$ On the downside, the failure to include changes in the stock of human-made capital casts doubt as to whether the GPI satisfies Hicks' central criterion. It therefore potentially weakens the theoretical case for the GPI.

In order to compare the ability of the GPI and NNP to satisfy Hicks' central criterion, let us consider how the circumstances associated with a number of hypothetical events would be represented by Equations (1) and (2). To simplify matters, let us assume the following:

- there are no new discoveries of non-renewable resources

- $\quad$ productivity gains apply equally to the production of new producer and consumer goods

- $\quad$ at all times, $S C D=E C D$ and $P Y=P O$.

The latter assumption means that the GPI equation reduces to:

$$
\mathrm{GPI}=C-L N C S
$$

The following is assumed to exist at year $Y_{0}$ :

- $C_{0}=500$

- $\quad$ human-made capital $\left(K h_{0}\right)=200$

- $\quad$ natural capital $\left(K n_{0}\right)=1,000$

- $\quad$ total capital $\left(K_{0}\right)=K h_{0}+K n_{0}=1,200$

\section{Example \# 1}

In the first case, both human-made capital and natural capital remain unchanged in year $Y_{1}$ as does the consumption level. That is:

- $C_{1}=500$

- $\quad$ human-made capital $\left(K h_{1}\right)=200$

- $\quad$ natural capital $\left(K n_{1}\right)=1,000$ (i.e., $\left.L N C S=0\right)$

- $\quad$ total capital $\left(K_{1}\right)=K h_{1}+K n_{1}=1,200$

- $\Delta K=0$

- there has been no productivity increase

The two accounting identities are:

- $\quad \mathrm{NNP}=500$

- $\mathrm{GPI}=500$

As can be seen, NNP and the GPI are of the same value. But do they both represent sustainable consumption/welfare? In both instances, they may not. Although humanmade capital and natural capital have remained intact, sustainability still depends on what 
form of natural capital is being exploited. If it is entirely a renewable resource, the consumption/welfare level is sustainable. If at least some of the natural capital utilised is a non-renewable resource, the constancy of natural capital implies that some additional renewable natural capital has been cultivated to replace it. Provided the cultivated resource is a perfect substitute for the non-renewable resource, the consumption/welfare level is again sustainable. However, if some of the non-renewable resource being utilised is non-substitutable, the consumption/welfare level is not sustainable.

I should point out that the GPI, like NNP, does not differentiate between different types of natural capital and would not reveal the unsustainability of the latter example. Overall, the GPI and NNP fail to satisfy Hicks' central criterion when economic activity involves the exploitation of non-renewable resources with no known renewable resource substitutes.

\section{Example \# 2}

In the second case, human-made capital rises in year $Y_{1}$ by the same amount that natural capital declines. The consumption level remains unchanged. That is:

- $C_{1}=500$

- human-made capital $\left(K h_{1}\right)=250$

- $\quad$ natural capital $\left(K n_{1}\right)=950$ (i.e., $L N C S=50$ )

- $\quad$ total capital $\left(K_{1}\right)=K h_{1}+K n_{1}=1,200$

- $\Delta K=0$

- there has been no productivity increase

The two accounting identities are:

- $\quad \mathrm{NNP}=500$

- $\mathrm{GPI}=450$

This second case represents the fishing boat/fish stocks example I referred to earlier. While NNP again equals 500, the GPI equals 450. Since NNP conflates human-made capital and natural capital and there is no productivity increase (i.e., there is a straight conversion of overexploited natural capital into additional human-made capital), NNP overstates the sustainable consumption/welfare level. In other words, there is more human-made capital available for future production but there is insufficient natural capital to provide the low entropy resource flow required to generate a future consumption level of 500 .

Interestingly, it is the GPI, not NNP, which satisfies Hicks' central criterion in this case (i.e., indicates the deleterious impact of current actions on future consumption/ welfare).

\section{Example \# 3}

On this occasion, both human-made capital and natural capital remain unchanged in year $Y_{1}$. However, the consumption level increases. That is: 
- $C_{1}=550$

- $\quad$ human-made capital $\left(K h_{1}\right)=200$

- $\quad$ natural capital $\left(K n_{1}\right)=1,000$ (i.e., $L N C S=0$ )

- $\quad$ total capital $\left(K_{1}\right)=K h_{1}+K n_{1}=1,200$

- $\Delta K=0$

- there has been a productivity increase

The two accounting identities are:

- $\quad \mathrm{NNP}=550$

- $\mathrm{GPI}=550$

The increase in productivity has enabled the consumption level to rise in $Y_{1}$ without having to reduce the stock of either form of capital. A productivity rise of this nature can emerge in the form of: (a) an increase in the productivity of human-made capital (i.e., more goods can be produced from the same low entropy resource flow); and/or (b) an increase in the productivity of renewable natural capital (i.e., more goods can be produced from a larger sustainable resource flow made possible through better renewable resource management).

Whether the value of 550 for both NNP and the GPI is sustainable depends, again, on what form of natural capital is being exploited. Once more, if it is entirely a renewable resource, the consumption/welfare level is sustainable. However, if there is some reliance on non-renewables and a portion of it is non-substitutable, a consumption/welfare level of 550 is unsustainable. Because there has been a productivity increase, the sustainable consumption/welfare level may still be more than the 500 units in year $Y_{0}$ (i.e., be between 500 and 550). But if a considerable quantity of a non-substitutable, nonrenewable resource has been utilised, it is possible, despite the productivity increase, for sustainable consumption/welfare to be less than 500 .

Whether both indicators satisfy Hicks' central criterion depends on the circumstances regarding the type of natural capital being exploited and the existence of substitution possibilities between renewable and non-renewable resources. Overall, neither indicator fares better than the other in this hypothetical example.

\section{Example \# 4}

In the fourth example, human-made capital rises in year $Y_{1}$ and natural capital remains unchanged. The consumption level is also unchanged. That is:

- $C_{1}=500$

- $\quad$ human-made capital $\left(K h_{1}\right)=250$

- $\quad$ natural capital $\left(K n_{1}\right)=1,000$ (i.e., $L N C S=0$ )

- $\quad$ total capital $\left(K_{1}\right)=K h_{1}+K n_{1}=1,250$

- $\Delta K=50$

- there has been a productivity increase 
The two accounting identities are:

- $\quad \mathrm{NNP}=550$

- $\mathrm{GPI}=500$

Not unlike the previous example, there has been a productivity increase. However, it is not the current consumption level which has been augmented but the stock of human-made capital (i.e., the potential to increase future consumption). Because the GPI ignores any changes in the stock of human-made capital, it has a lower value than NNP.

Without repeating myself too much, whether the value of 550 for NNP is sustainable will once more depend on the circumstances regarding the type of natural capital being exploited and substitution possibilities between renewable and non-renewable resources. If the sustainable consumption level is something between 500 and 550, NNP will overstate sustainable consumption/welfare but the GPI will understate it. A sustainable consumption level of less than 500 (where a considerable quantity of a non-substitutable, non-renewable resource has been utilised) will result in both indicators overstating sustainable consumption/welfare.

Irrespective of what the sustainable consumption level is, there will obviously be a disparity between what NNP and the GPI measure. What will this disparity represent? It will represent the failure of the GPI to incorporate the additional productive capacity of the economy by not including changes in the stock of human-made capital. It is this failure which forms the basis for Harris's central criticism of the GPI.

\section{Example \# 5}

In this particular case, consumption rises in year $Y_{1}$, human-made capital remains unchanged, and natural capital declines. That is:

- $C_{1}=550$

- $\quad$ human-made capital $\left(K h_{1}\right)=200$

- $\quad$ natural capital $\left(K n_{1}\right)=950$ (i.e., $\left.L N C S=50\right)$

- $\quad$ total capital $\left(K_{1}\right)=K h_{1}+K n_{1}=1,150$

- $\Delta K=-50$

- there has been no productivity increase

Our two accounting identities are:

- $\quad \mathrm{NNP}=500$

- $\mathrm{GPI}=500$

With no productivity gain from $Y_{0}$ to $Y_{1}$, the increase in consumption arises merely from the overexploitation of natural capital. Because the GPI accounts for the depletion of natural capital, its value is the same as NNP. Again, whether a value of 500 constitutes the sustainable consumption/welfare level depends on the natural capital being exploited and substitution possibilities. 
Let's assume that only renewable natural capital is being exploited. One could be excused for thinking that 500 is the sustainable consumption/welfare level. But is it? Since there is less natural capital at the end of year $Y_{1}$, this amounts to a reduction in the sustainable resource flow available for future production. In effect, the productive capacity of the economy has diminished. Like example \# 2, the sustainable consumption level will have now fallen to something akin to 450. In these circumstances, NNP and the GPI will overstate sustainable consumption/welfare despite their calculation involving a deduction for natural capital depletion. ${ }^{10}$

\section{Example \# 6}

In the final case, consumption rises in year $Y_{1}$, human-made capital declines, and natural capital remains unchanged. That is:

- $C_{1}=550$

- human-made capital $\left(K h_{1}\right)=150$

- natural capital $\left(K n_{1}\right)=1,000$ (i.e., $L N C S=0$ )

- $\quad$ total capital $\left(K_{1}\right)=K h_{1}+K n_{1}=1,150$

- $\Delta K=-50$

- there has been no productivity increase

Our two accounting identities are:

- $\quad \mathrm{NNP}=500$

- $\mathrm{GPI}=550$

This final example is very similar to the previous example except the form of capital being sacrificed to augment current consumption is human-made capital rather than natural capital. Not unlike example \# 4, the GPI has a different value than NNP because the change in the stock of human-made capital is ignored in the calculation of the GPI. Again, it is this omission which Harris is critical of. As for whether the value of 500 for NNP amounts to a sustainable consumption level, all the issues previously mentioned apply once more.

There is, however, a slight difference between this situation and the circumstances surrounding example \# 5. Let's assume that only renewable natural capital is being exploited. Since the stock of natural capital has remained intact, the sustainable resource flow is unchanged. The opportunity therefore still exists to rapidly restore the stock of human-made capital to its previous level of 200. This would reinstate the economy's productive capacity and allow consumption to return again to 500 units. In direct contrast, the lower resource flow resulting from the depletion of natural capital in example \# 5 means that consumption is reduced to 450 units until such time as renewable natural capital is increased to its original level of 1,000. Given the slow growth rates of renewable resources, this will take some considerable time. In the meantime, the reduced resource flow will not only restrict the consumption level, it will limit the nation's ability to maintain its stock of human-made capital. 
This discrepancy clearly demonstrates the critical nature of natural capital - whilst human-made capital is necessary to produce consumption goods, it is useless unless supported by sufficient quantities of complementary forms of natural capital. And while the drawing down of human-made capital reduces a nation's ability to consume in future years, the economy's productive capacity can be reinstated quite rapidly provided natural capital is kept intact. If natural capital is being liquidated, there is no guarantee at all of restoring productive capacity regardless of how much human-made capital has been accumulated in the past. This situation is made worse if the nation in question is heavily reliant upon non-renewable resources which happen to be devoid of renewable resource substitutes.

What can we conclude from these hypothetical examples? At best, NNP is only a marginally more superior indicator of sustainability than the GPI. NNP has the advantage of including changes in human-made capital; however, an increase in the stock of humanmade capital only represents an increase in future consumption possibilities if it is both productivity-induced (i.e., its accumulation has not involved the sacrifice of natural capital) and productivity-enhancing (i.e., its accumulation enables more consumption goods to be produced from a given natural resource flow). Since the addition of any net rises in human-made capital is likely to include straight conversions of natural capital to human-made capital, NNP will almost certainly overstate sustainable consumption. And while the GPI avoids the problems associated with the conflation of human-made and natural capital by omitting changes in human-made capital altogether, it fails to incorporate any productivity gains that would otherwise indicate a boost to future consumption possibilities.

That is not to say that the GPI ignores productivity gains completely since any portion of a rise in current consumption caused by an increase in productivity is fully reflected in the GPI by a rise in the consumption item (see example \# 3). Only future consumption possibilities are ignored (see example \# 4). As far as being able to indicate the reduction in future consumption possibilities that may arise from a reliance on non-renewable resources with no known renewable resource substitutes, both the GPI and NNP are deficient.

It would seem, therefore, that an important issue requiring resolution is whether a measure of income should principally capture experiential welfare or indicate if an economy is on a sustainable path. I pose this choice if only because the above exercises demonstrate that a measure of income cannot achieve both. And while I don't believe that income should completely overlook the impact of current actions on future welfare possibilities, it will never be possible to design a measure of income that fully satisfies Hicks' central criterion. For this reason, I believe indicators of sustainability are best left to measures of wealth, or better still, individual measures of human-made and natural capital given their complementarity. Indeed, I would go further and argue that natural capital should be further separated into renewable resources, non-renewable resources, and critical natural capital, such as vital ecosystems. ${ }^{11}$ Comparisons of a nation's ecological footprint and biocapacity would also be of great value in this regard (Wackernagel et al., 1999).

Of course, it will be claimed that NNP is already a measure of wealth. It is, in fact, a 'wealth-like' measure, but not a true measure of wealth because it includes present consumption (Boulding, 1962). ${ }^{12}$ What a nation consumes today is not part of its current 
wealth even though it contributes to its current welfare. Wealth is what remains following consumption that can be passed on over time. But, importantly, future consumption possibilities locked up in current wealth are not part of a nation's current welfare.

Overall, if an improved economic indicator of sustainability is desired, we would be better served by the expression $\Delta K$, not $C+\Delta K$. Something equivalent to $\Delta K-$ commonly referred to as Genuine Savings (GS) - is now being calculated to assess the sustainability of nations (see Pearce and Atkinson, 1993; Hamilton, 1994 and 2003; Pearce et al., 1996; Hamilton and Clemens, 1999; Hamilton, 2003). The GS is an improvement on NNP, but it also suffers from the conflation of human-made and natural capital and issues concerning the use of non-renewable resources.

I personally believe that income should be biased towards experiential welfare with some incorporation of the impact of current activities on future welfare possibilities. As it is, the GPI already includes the impact of natural capital depletion but should, on reflection, also include changes to future welfare possibilities brought about productivity gains embodied in newly created human-made capital. However, all income measures should be supplemented by more appropriate sustainability indicators which, in the case of natural capital, ought to be based on biophysical assessments and the capacity of resource stocks to generate a sustainable resource flow.

Being a GPI supporter myself, I have not leaned towards measures of experiential welfare simply to justify the GPI. I frankly believe that knowing what level of welfare is currently being experienced is valuable information. Also, despite considerable room for improvement, I believe the GPI already enables us to measure experiential welfare with some degree of accuracy. At the same time, no measure of income will ever come close to reflecting future welfare possibilities. Why sacrifice the opportunity to capture experiential welfare by attempting to satisfy a criterion better indicated by measures of wealth/capital?

Finally, and this might best validate the extended version of Fisher's concept of income and the theoretical foundation supporting the GPI, I believe the GPI in its present form already has the capacity to warn us of impending unsustainability. How? Ecological economists have for some time been distinguishing between an optimal macroeconomic scale and a maximum sustainable scale. The latter relates directly to the ecological sustainability of economic systems. That is, the maximum sustainable scale is a point beyond which further growth of an economy requires a throughput of matter-energy that cannot be ecologically sustained (i.e., exceeds the regenerative and waste assimilative capacities of the ecosphere). The optimal macroeconomic scale constitutes a point beyond which the additional benefits of growth are exceeded by the additional costs - an inevitable outcome given the applicability of the principles of diminishing marginal benefits and increasing marginal costs in a finite world subject to the first and second laws of thermodynamics and where human beings possess a limited physiological capacity to experience well-being. Growth beyond the optimal scale is significant because it leads to a decline in the economic welfare generated by the economic process.

Should the pursuit of GDP growth continue, ecological economists believe the optimal macroeconomic scale will be surpassed prior to reaching the maximum sustainable scale. In other words, growth will be rendered 'uneconomic' well before it becomes ecologically unsustainable. Because the GPI involves having to subtract the uncancelled costs of economic activity from the uncancelled benefits, it is ideally suited to indicate whether the growth of an economy is economic or uneconomic. For example, if both the GPI and real GDP are rising, this suggests that the marginal benefits of growth 
are greater than the marginal costs and that growth is economic. However, if the GPI abruptly declines while real GDP continues to rise, this suggests that marginal costs have exceeded the marginal benefits and that growth has become uneconomic. Given that the optimal scale will be surpassed before the maximum sustainable scale is reached, a sudden fall in the GPI indicates that the economy is perhaps only a decade or so away from becoming unsustainable. It is interesting to note that the GPI of the USA and a number of European countries began to decline in the late 1960s/early 1970s about a decade prior to their respective ecological footprints exceeding their biocapacity (Wackernagel et al., 1999).

In all, the ability of the GPI to warn us of impending unsustainability comes not from satisfying Hicks' central criterion, but by comparing the benefits and costs of growth i.e., the experiential welfare gained from economic activity less the experiential welfare lost from sacrificing the natural capital services necessary to fuel the economic process. Of course, being able to signal impending unsustainability doesn't mean that the GPI can inform us at what point an economy starts to exceed its maximum sustainable scale. That, as I have argued, requires appropriate wealth/capital measures.

Having said all this in favour of the GPI, there admittedly remains the issue of whether the various items that make up the GPI accurately reflect the benefits and costs of economic activity. Even if they do, it is still debatable as to whether a decline in the GPI reflects excessive growth, a grossly inefficient allocation of resources, a deteriorating institutional framework, and/or bad public policies. I'll have more to say about these aspects in the next section of the paper.

\section{Response to some specific points raised by Harris}

Apart from the criticism directed at the GPI in relation to Hicks' central criterion, Harris raises a number of other key issues in his paper. In this section, I will respond to some of the main points that need to be addressed.

Criticism (p.5): Harris suggests that advocates of the GPI are motivated by the idea that the scale of economic development is (likely to be) unsustainable and that a crucial threshold - i.e., a point where economic systems cease to be ecologically sustainable has already been passed. Harris continues by saying that GPI advocates are of the belief that sustainability measures in the neoclassical tradition fail to provide evidence of threshold-crossing whereas indicators grounded in the ecological economics paradigm, such as the GPI and the ecological footprint, are able to do so.

Response: This point has already been addressed to a large extent. It is an unfortunate fact that some GPI advocates have strongly promoted the GPI as a potential sustainability indicator and Harris is excused for believing that all GPI proponents think alike on this matter. ${ }^{13}$ The great majority of GPI advocates — including myself — have never argued the case for the GPI along these lines.

I mentioned above that many ecological economists have made a clear distinction between the optimal macroeconomic scale and the maximum sustainable scale. Because the GPI separates the benefits and costs of economic activity, and thus says something about the economic/uneconomic nature of the economic process, it is growth beyond the optimal scale which the GPI is designed to reveal, not growth beyond a sustainability threshold (maximum sustainable scale). As already mentioned, measures of 
capital/wealth or biophysical indicators, such as a comparison between a nation's ecological footprint and biocapacity, are better able to reveal something about the current scale of economic systems relative to the maximum sustainable scale.

Putting aside the difference in opinion as to what the GPI indicates, GPI advocates would unanimously agree that indicators in the neoclassical tradition fail to indicate when an economy has surpassed a sustainability threshold. For the ecological economists who believe the GPI is an indicator of economic/uneconomic growth, they would go much further and argue that neoclassical indicators fail to reveal anything about whether the scale of the economy has exceeded a 'desirability' threshold.

Criticism (p.7): Harris states that one of my key complaints about the Hicksian version of income is that it is a product-based measure and that Fisher's consumption-based focus is the preferred means of capturing income. Harris then goes on to say that I have neglected to recognise that Hicks' preferred measure of income is very much consumption-based.

Response: The previous section of the paper makes it quite clear that I recognise Hicksian income as a consumption-based indicator. Still, one can easily alter their tune having said something different in the past. I don't consider myself to be guilty of this. In the paper to which Harris refers (Lawn, 2003), I state Hicks' definition of income in terms of the maximum amount that can be consumed and then proceed to use this consumption-based definition to reveal the shortcomings of GDP as a measure of income. To be precise, I invite the reader to conduct a Hicksian examination of GDP by asking the following question: "Can a nation's entire GDP be consumed without undermining its ability to produce and consume the same GDP in the future?" (italics added).

However, I'd be dishonest if I denied referring to Hicksian income in my 2003 paper as something equivalent to a product-based measure. But I did this as a convenient means of differentiating Hicks' emphasis on the physical goods consumed from Fisher's emphasis on psychic income as the end purpose of economic activity. I still stand by the usefulness of this distinction given that Hicksian income, when valued in real terms (constant prices), is effectively based on the quantity of goods consumed irrespective of their content and genuine contribution to human well-being. Given there is no necessary correlation between the quantity of goods consumed and the psychic income generated, the Hicksian concept of income is, in my view, very much product-based.

Criticism (p.8): Harris suggests that the distinction between the physical (Hicksian) and experiential (Fisherian) doesn't really amount to a difference at all. That is, even if Hicksian income is product-based, the accounting result is the same in both cases.

Response: In practical terms, I agree with Harris since, as the hypothetical examples revealed, the value of the consumption item used to calculate the GPI is the same as the value of consumption expenditure used in the calculation of Hicksian national income. But this step is only performed because it is impossible to measure psychic income directly. Nevertheless, it is the experiential focus of Fisherian income that results in the GPI going well beyond consumption to include benefit and cost items that reflect the additional psychic income and psychic outgo aspects of the economic process (see Equation 2). Of course, this leaves open the question as to whether additional psychic income and psychic outgo factors ought to be included in a measure of national income. I believe they should, particularly if income is preferably based on experiential welfare. But even if income should incorporate Hicks' central criterion, the criterion itself implies an expectation of being "as well off" at the end of a period as at the beginning 
(Hicks, 1946, p.172). If the present value of future consumption is the same as it was in the previous accounting period, are people "as well off" if they have worked more hours in an occupation they dislike in order to maintain their consumption levels? Clearly not. As such, confining income to consumption can only be justified if consumption alone constitutes the summum bonum of the economic process - something very few people would ostensibly agree with.

Comment by Harris (pp.10-11): At one particular point in the discussion, Harris refers to a steady-state setting characterised by a constant underlying stock of capital. Harris then asserts that, in such a setting, Fisherian income, Hicksian income, and national output would be identical.

Response: Harris does not, unfortunately, stipulate what he means by national output. If it is real GDP, the assertion is incorrect since to keep the stock of human-made capital intact, some portion of national output must be set aside to replace worn out producer goods. Hence, in a steady-state setting, GDP includes gross investment, which must be positive, whereas Hicksian income or NNP includes net investment, which would be zero. Real GDP must, therefore, be greater in magnitude than Hicksian income although it need not be larger than the GPI given the possibility of other psychic income items to far exceed psychic outgo items.

Harris also fails to inform us as to what he means by a steady-state stock of capital. Is it the stock of human-made capital (producer goods) or the combined stock of humanmade and natural capital? This is important given that a constant capital stock involving a rise in human-made capital to offset a decline in natural capital results in Hicksian income overstating sustainable consumption (hypothetical example \# 2). Hicksian income is also higher than the GPI in this situation - hence the two measures of income are not necessarily the same in a steady-state milieu.

I should also add that when ecological economists refer to the steady-state, they separate human-made capital (economy) from natural capital (ecosphere). ${ }^{14}$ Again, this is because of the complementarity between the two forms of capital. But more than having implications for income measurements, the complementary relationship between humanmade and natural capital provides, in part, the theoretical support for the ecological economic position on the unsustainability and uneconomic nature of continued growth. This, in turn, constitutes the motivation behind the establishment of the GPI (indicator of optimal macroeconomic scale) and the ecological footprint (indicator of maximum sustainable scale).

Criticism (pp.11-12): Harris invites the reader to consider a more dynamic setting plus what can be inferred from a time series of observations of the GPI, whether rising, flat, or declining. Given my preference for the Fisherian concept of income, Harris argues that I have interpreted a rise or decline in the GPI as a mere increase or decrease in "currently experienced economic welfare" with no reference as to what this means in terms of where an economy might be heading.

Response: As to my interpretation of the GPI as an indicator of "currently experienced economic welfare", it is worth reiterating that the value of the GPI is less than the total economic welfare being experienced because the economic welfare generated by economic activity (net psychic income) is reduced by the economic welfare lost as a consequence of sacrificing natural capital services. ${ }^{15}$ The difference between the two is, as I mentioned before, an indicator of the value added to nature by the economic process. 
With regards to what the GPI means in terms of the direction in which an economy is headed, I have already dealt with this in relation to the optimal macroeconomic scale and the impending unsustainability of the economy once the optimal scale has been exceeded. In sum, I believe it is incorrect to suggest that nothing can be interpreted from the GPI as to where the economy is headed.

Criticism (p.14): Harris is critical of the manner in which GPI advocates, by interpreting a decline in the GPI as evidence of growth beyond a desirable or optimal scale, make the giant leap from correlation to causation. In other words, GPI advocates are effectively guilty of saying "if the GPI is falling as real GDP continues to rise, then it follows that the GPI must be falling because real GDP continues to rise".

Response: When reporting on GPI results in my 2003 paper and elsewhere I have avoided saying that a decline in the GPI is always a categorical indication of an excessive scale of economic activity. Indeed, in Lawn (2007, Chapter 9), I argued that the fall in Australia's GPI over the past thirty years could be just as well explained at various stages by rising inefficiencies which, I further surmised, were the likely result of inappropriate government policies. To be frank, some econometric work to support the link between excessive growth and a falling GPI is urgently required. Moves are currently being made to deal with this shortcoming and statistical results should appear in the not-too-distant future.

In any case, I think it is reasonable to assume that a decline in the GPI constitutes solid ground for believing an economy has grown beyond its optimal scale. Why? Firstly, without repeating myself too much, continuous physical expansion of an economic system is not possible - biophysical limits to growth are a reality. Secondly, no matter how efficiently resources are allocated, one cannot expect the welfare generated by the economic process to continue rising immediately prior to the economy plummeting over an ecological precipice. For this reason, uneconomic growth is also a reality, as is the idea that an optimal macroeconomic scale exists well short of the maximum sustainable scale. Should economic expansion continue, it is simply a matter of 'when' growth becomes uneconomic, not 'if'. Provided the GPI measures the net benefits of growth with sufficient accuracy, any claim that a declining GPI indicates excessive growth cannot be discredited on the basis that uneconomic growth can forever be averted. ${ }^{16}$

Thirdly, it is possible, as I have said earlier, for a fall in the GPI to be the result of inefficiencies, institutional decay, and/or bad policies. However, consider the fact that the GPI of all the industrialised nations where GPI studies have been conducted began to fall at about the point where per capita GDP reached USD15,000-20,000 (Max-Neef, 1995). It is difficult to believe that this could have been due to a uniform and continuous deterioration in the allocation of resources and/or bad policy settings. This is not to say that resources aren't being inefficiently allocated or that policy settings and institutions in these countries are ideal. No country operates Pareto efficiently at its prevailing scale of economic activity. But it is reasonable to presume that, apart from the continuing obsession with growth, most economic policy setting has improved over time through advances in economic theory and a better understanding of how economies function. It would therefore seem reasonable to assume that whatever difference there is between the actual and potential GPI for any given economic scale - which has gone unrealised due to bad policy — it hasn't been increasing to any major degree in recent decades. If so, growth beyond the optimal scale would seem to be the logical explanation for the widespread decline of the GPI in the industrialised world. 
Criticism (p.14): One of the items employed in the calculation of the GPI is an index of distributional inequality. The index is used to weight consumption expenditure on the basis that the aggregate welfare contribution of any given level of consumption declines/rises as the distribution of income deteriorates/improves. This step is undertaken given that the marginal consumption benefits of the rich are less than that of the poor (i.e., an extra dollar of consumption adds more to the welfare of the poor than one less dollar of consumption reduces the welfare of the rich) (Robinson, 1962; Easterlin, 1974 and 2001; Abramowitz, 1979). When demonstrating how GPI advocates turn correlation into causation, Harris refers to this item and the welfare adjustment associated with it. However, in making his point, Harris contends that GPI advocates are effectively implying that: (a) continued growth must be correlated with a growing inequality of income; (b) given (a), any increase in the inequality of income must be the consequence of growth; and (c) the growth of the economy is dependent on a deterioration in the distribution of income.

Response: As explained, the weighting of consumption expenditure on the basis of distributional changes is undertaken for good empirical reasons. Incorporating this item into the GPI in no way suggests that growth is automatically linked to a deterioration in the distribution of income or that greater income inequality must only be a function of growth. Nevertheless, if a more unequal distribution of income happens to be, for a period of time, the result of continuing growth, its negative impact on the welfare contribution of consumption is quite rightly captured by the GPI. But the GPI will also capture any improvement in the distribution of income caused by growth. In fact, as my work on Australia has revealed, it is quite feasible for the latter to occur as the GPI is falling, or for the former to occur while the GPI is rising. Admittedly, the most common situation has involved the deterioration in the distribution of income accompanying a decline in the GPI. However, the predominance of this trend can in no way be attributed to an accounting procedure that is based, in the Australian case, on variations over time in the Gini coeffecient. It is merely a reflection of what is happening within the Australian economy.

Criticism (p.14): When referring to other items used in the calculation of the GPI, Harris is critical of the fact that there is no "compelling model to explain how, when item A goes up, item B inevitably goes down."

Response: I confess that more should be done by GPI advocates to justify the inclusion of some individual GPI items and the methods used to value them. On a positive note, a number of GPI practitioners are beginning to address these issues (Lawn, 2005). As far as explaining the links between the various GPI items, I see no reason for this. To begin with, GPI advocates are not claiming that a causal relationship necessarily exists between the individual items. Nor, given that the GPI items are calculated independently of each other, is the GPI deliberately or inadvertently constructed on this basis. In my view, the GPI has been designed in a very non-biased way to include the major positive and negative impacts that the economic process has on human welfare. ${ }^{17}$ The items have not been chosen because growth at all times impacts on individual items in one direction only (i.e., always positively or negatively), or because there is any causal relationship between the various items (e.g., increased consumption always leads to an increased cost of crime). 
Criticism (p.15): Returning to the issue regarding whether a downturn in the GPI indicates that the economy has grown beyond the optimal scale, Harris argues that rich nations operating on a similar scale of economic activity may experience similar rates of growth but entirely different outcomes in terms of income inequality or, presumably, any other item that makes up the GPI (e.g., cost of crime, air pollution, or non-renewable resource depletion). In other words, the change in the value of an item may be more a function of policy settings than excessive growth. As a consequence, downturns in the GPI are potentially reversible without the need to downsize to a steady-state economy. ${ }^{18}$

Response: I agree with Harris regarding different outcomes for similar countries with similar rates of growth. In the USA, for example, income inequality is much greater than in Europe and therefore has a more significant impact on the GPI. Conversely, in Europe, it is the cost of unemployment which is more influential. These differences, no doubt, are very much a function of the different labour market and welfare system policies in the USA vis-à-vis most European countries. This aside, the general flavour of macroeconomic and social policies in all nations is pro-growth. Hence, the varying policies implemented in different countries are basically a reflection of the alternative approaches adopted to promote growth and to minimise its negative side-effects. Ultimately, however, it is the uniformly pro-growth approach to policy and the strong likelihood that unrealised potential has changed little in recent decades which convinces me that excessive growth is the main cause of the declining GPI phenomenon in the industrialised world.

I said earlier that there will always be some disparity between the actual and potential GPI for any given economic scale. Should the gap be substantial, it is possible, as Harris suggests, for a declining GPI to be overturned without having to downsize the economy. The simplest possibility exists if the fall in the GPI is the product of 'bad' growth rather than 'excessive' growth (i.e., growth that is inefficient, inequitable, and exceedingly exploitative of the natural environment). All that would be needed here is better policy.

For a nation which has grown its economy beyond the optimal scale, a nation can overturn the decline in the GPI if it can secure exceptionally large efficiency improvements. However, the GPI would still be less than the value it would otherwise be if the economy was operating at the optimal scale. More importantly, should the economy keep growing, efficiency improvements must increase in magnitude to prevent the GPI from eventually falling. Unfortunately, as thermodynamic limits are approached, efficiency gains become more difficult to secure and smaller in magnitude. Thus, for an economy beyond the optimal scale, the efficiency option is merely a short-term solution. Generally speaking, once the optimal scale has been exceeded, the downsizing to a steady-state economy is the best and technically simplest means of increasing the GPI. Continued growth, regardless of the rate of efficiency gains, must inevitably result in a declining GPI. Eventually it must lead to the more dire situation of an economy in excess of its maximum sustainable scale.

\section{Concluding remarks}

In what constitutes the greatest challenge yet to the GPI, Harris's critique of the GPI leaves its proponents with no choice other than to respond to the many criticisms raised — not the least being that the GPI appears to violate Hicks' central criterion of having to 
keep income-generating capital intact. I am more than willing to concede that the GPI, as an indicator of experiential welfare based on an extended version of Fisherian income, is a far from perfect measure of income in the strict Hicksian tradition. But neither is NNP since, as shown, it conflates human-made and natural capital, it overlooks what substitution possibilities exist between renewable and non-renewable resources (which is critical if the economy is heavily reliant upon non-substitutable forms of the latter), and largely ignores the waste assimilative and life-support services provided by the ecosphere.

Because the calculation of the GPI involves the need to subtract from net psychic income the economic welfare lost from sacrificed natural capital services (i.e., from depleted natural capital), there is little doubt that the GPI embodies considerable information regarding the future welfare implications of current actions. But the information is incomplete. As such, changes to future welfare possibilities brought about productivity gains embodied in newly created human-made capital should in some way be incorporated into the GPI. But the GPI should not be rejected because, like any other measure of income, it fails to satisfy Hicks' central criterion. To the contrary, the GPI can help determine whether the economy has exceeded its optimal scale which, in turn, can provide a genuine warning of impending unsustainability. But we should always leave sustainability indicators to measures of capital/wealth or biophysical indicators such as the ecological footprint.

\section{References}

Abramowitz, M. (1979), 'Economic growth and its discontents', in M. Boskin (ed.), Economics and Human Welfare, Academic Press, New York.

Asheim, G. (1994), 'Net national product as an indicator of sustainability', Scandinavian Journal of Economics, Vol. 96, pp.257-265.

Boulding, K. (1962), A Reconstruction of Economics, Second Edition, Harper, New York.

Boulding, K. (1966), 'The economics of the coming spaceship Earth', in H. Jarrett (ed.), Environmental Quality in a Growing Economy, John Hopkins University Press, Baltimore, pp.3-14.

Cobb, C., Halstead, T., and Rowe, J. (1995), 'If the GDP is up, why is America down?', The Atlantic Monthly, October, pp.59-78.

Daly, H. (1979), 'Entropy, growth, and the political economy of scarcity', in V. K. Smith (ed.), Scarcity and Growth Reconsidered, John Hopkins University Press, Baltimore, pp.67-94.

Daly, H. (1991), Steady-State Economics, Second edition with essays, Island Press, Washington DC, Chapter 10.

Daly, H. (1996), Beyond Growth, Beacon Press, Boston.

Daly, H. and Cobb, J. (1989), For the Common Good, Beacon Press, Boston.

Easterlin, R. (1974), 'Does economic growth improve the human lot?', in P. David and R. Weber (eds), Nations and Households in Economic Growth, Academic Press, New York.

Easterlin, R. (2001), 'Income and happiness: towards a unified theory', Economic Journal, Vol. 111, pp.465-484.

Fisher, I. (1906), Nature of Capital and Income, A. M. Kelly, New York.

Georgescu-Roegen, N. (1971), The Entropy Law and the Economic Process, Cambridge University Press, Cambridge, MA.

Hamilton, K. (1994), 'Green adjustments to GDP', Resources Policy, Vol. 20, pp.155-168.

Hamilton, K. (2003), 'Sustaining economic welfare: estimating changes in total and per capita wealth', Environment, Development, and Sustainability, Vol. 5, pp.419-436. 
Hamilton, K. and Clemens, M. (1999), 'Genuine savings rates in developing countries', World Bank Economic Review, Vol. 13, pp.333-356.

Hartwick, J. (1977), 'Intergenerational equity and the investing of rents from exhaustible resources, American Economic Review, Vol. 66, pp.972-974.

Hartwick, J. (1978), 'Substitution among exhaustible resources and intergenerational equity, Review of Economic Studies, Vol. 45, pp.347-354.

Hartwick, J. (1994), 'National wealth and net national product', Scandinavian Journal of Economics, Vol. 96, pp.253-256.

Harris, M. (2008), 'On income, sustainability and the 'microfoundations' of the GPI', International Journal of Environment, Workplace, and Employment, Vol. 3, pp.119-131.

Hicks, J, (1946), Value and Capital, Second Edition, Clarendon, London.

Lawn, P. (1999), 'On Georgescu-Roegen's contribution to ecological economics', Ecological Economics, Vol. 29, pp.5-8.

Lawn, P. (2000), Toward Sustainable Development: An Ecological Economics Approach, CRC Press, Boca Raton.

Lawn, P. (2003), 'Theoretical foundation to support the Index of Sustainable Economic Welfare (ISEW), Genuine Progress Indicator (GPI), and other related indexes', Ecological Economics, Vol. 44, pp.105-118.

Lawn, P. (2004), 'How important is natural capital in sustaining real output? Revisiting the natural capital/human-made capital substitutability debate', International Journal of Global Environmental Issues, Vol. 3, pp.418-435.

Lawn, P. (2005), "An assessment of the valuation methods used to calculate the Index of Sustainable Economic Welfare (ISEW), Genuine Progress Indicator (GPI), and Sustainable Net Benefit Index (SNBI)', Environment, Development, and Sustainability, Vol. 7, pp.185-208.

Lawn, P. (2007), Frontier Issues in Ecological Economics, Edward Elgar: Cheltenham, UK.

Lawn, P. and Sanders, R. (1999), 'Has Australia surpassed its optimal macroeconomic scale? finding out with the aid of benefit and cost accounts and a sustainable net benefit index', Ecological Economics, Vol. 28, pp.213-229.

Mäler, K-G. (1986), 'Comment on R. M. Solow, "On the intergenerational allocation of natural resources", Scandinavian Journal of Economics, Vol. 88, pp.151-152.

Max-Neef, M. (1995), 'Economic growth and quality of life', Ecological Economics, Vol. 15, pp.115-118.

Pearce, D. and Atkinson, K. (1993), 'Capital theory and the measurement of sustainable development: an indicator of weak sustainability', Ecological Economics, Vol. 8, pp.103-108.

Pearce, D., Hamilton, K. and G. Atkinson (1996), 'Measuring sustainable development: progress on indicators', Environment and Development Economics, Vol. 1, pp.85-101.

Robinson, J. (1962), Economic Philosophy, C.A.Watts \& Co, London.

Solow, R (1986). 'On the intergenerational allocation of natural resources', Scandinavian Journal of Economics, Vol. 88, pp.141-149.

Stockammer, E., Hochreiter, H., Obermayr, B. and Steiner, K. (1997), 'The index of sustainable economic welfare (ISEW) as an alternative to GDP in measuring economic welfare: the results of the Austrian (revised) ISEW calculation, 1955-1992', Ecological Economics, Vol. 21, pp.19-34.

Wackernagel, M., Onisto, L., Bello, P., Callejas Linares, A., Susana López Falfán, S., Méndez García, J., Suárez Guerrero, A. I., and Ma. G. Suárez Guerrero (1999), 'National natural capital accounting with the ecological footprint concept', Ecological Economics, Vol. 29, pp.375-390.

Weitzman, M. (1976), 'On the welfare significance of national product in a dynamic economy', Quarterly Journal of Economics, Vol. 90, pp.156-162. 


\section{Notes}

1 Solow (1986) and Hartwick (1994) liken NNP to the 'interest' on an appropriately defined stock of capital.

2 As we have seen from Equation (1), Hicksian income includes the future consumption possibilities embodied the capital stock.

3 This in no way suggests that the logic behind the GPI or similar alternative indicator has not been explicated in the past. Cobb et al. (1995) and Stockhammer et al. (1997) have provided elaborate rationales for the GPI, whilst Daly has frequently referred to Fisher's distinction between income and capital as the basis for useful accounting identities (Daly, 1979; 1991; 1996). In addition, a theoretical framework was sketched in Lawn and Sanders (1999) whereby the various GPI items were separated into benefit and cost accounts before the final index value was calculated.

4 By natural capital services I mean the source, sink, and life-support services provided freely by the ecosphere (natural capital).

$5 \quad$ Not all GPI advocates would necessarily agree with me in this point.

6 For a full list of the items typically used to calculate the GPI, see Lawn (2003).

7 The ISEW and GPI essentially differ in terms of name only. The indicator was first coined an ISEW when constructed by Daly and Cobb (1989). To increase its public appeal, its name was altered to the GPI by Cobb et al. (1995).

8 This point has also been emphasized by Mäler (1986), among many others.

9 Whereas early GPI studies included the change in human-made capital above/below the amount required to maintain the per worker stock of producer goods, more recent GPI studies have excluded changes in human-made capital altogether. The latter has been done so that the GPI is more consistent with the Fisherian income concept.

10 Notwithstanding this, a hypothetical example of this nature demonstrates that the GPI at least says something about what might happen to future welfare possibilities - indeed, at least as much as what NNP informs us.

11 I recommended this in my 2003 paper (Lawn, 2003) and have also done so elsewhere (e.g., Lawn, 2005).

12 As Boulding (1962, Chapter 8) has demonstrated, consumption is the equivalent of destroyed capital/wealth.

13 At one point, Harris refers to the interpretation of a downturn in the GPI as "the economy exceeding its (optimal) sustainable scale". This suggests that Harris considers an 'optimal' scale and the 'maximum sustainable' scale to be the very same thing when, in the minds of ecological economists, they are not.

14 For example, ecological economists define a steady-state economy as one where the stock of human-made capital is constant in a physical sense (although not necessarily in a qualitative sense).

15 I must confess that I have previously referred to the GPI for a particular year as "an estimation of the sustainable economic welfare being experienced by a nation's citizens in that year" (Lawn, 2005).

16 In fact, in can be averted but only if, at the appropriate economic scale, a nation makes the transition to a steady-state economy.

17 I say non-biased because there are a number of positive GPI items (benefits) not included in a measure of GDP that are significantly large and increasing. Nonetheless, one could argue that some of the assumptions made in the calculation of the GPI items are biased. Harris highlights one potential bias in relation to the item reflecting the cost of family breakdown (endnote \# 8). This cost item is invariably based on the divorce rate. Harris raises the possibility that divorce could be welfare-improving, presumably on the basis that divorce brings to an end a dysfunctional relationship. While, to a point, I see the logic of Harris's argument, it is akin to 
saying that an increased number of visits to medical practitioners is welfare-improving because, in most instances, a person's health improves following the visit. Yet most people would view a rise in visitations as an indication of an undesirable increase in the rate of illness in society. There are other similar examples one can think of; for example, perhaps unemployment can be considered welfare-improving if it relieves people of demeaning occupations? By and large, as much as an actual divorce may solve a problem, it is a response to an initial problem which clearly has many negative welfare implications.

18 Transition to a steady-state economy is the usual recommendation made by ecological economists once the GPI begins to decline. 